\title{
MATERIALIDADES DA AUTORIA NA SESSÃO DE AUTÓGRAFOS
}

\author{
Lucas Piter Alves-Costa \\ Universidade Federal de Santa Maria \\ Centro de Artes e Letras \\ Departamento de Letras Vernáculas \\ Laboratório CORPUS
}

\author{
Marilda Aparecida Lachovski ${ }^{* *}$ \\ Universidade Federal de Santa Maria \\ Departamento De Letras Vernáculas \\ Santa Maria, RS, Brasil
}

\begin{abstract}
Resumo: Este artigo tem por objetivo aproximar as noções de autor, autoria e enunciado a partir, sobretudo, de pressupostos de Foucault $(2008,2009)$ e Costa (2016), em diálogo com Orlandi (1987, 1998, 2005), Gregolin (2003, 2004) e Pêcheux (2009), para, então, problematizar a dupla dimensão do nome de autor, a saber: o autor tomado como sujeito e como um enunciado. Em seguida, este trabalho discute sobre algumas materialidades próprias do nome de autor enquanto enunciado. Para isso, a discussão é pautada nos aspectos de uma sessão de autógrafos do discurso quadrinístico. Os resultados das reflexões aqui propostas reforçam a conceituação de enunciado complexo (COSTA, 2016) a partir da função que o nome de autor desempenha nos discursos que nele se fundam.
\end{abstract}

Palavras-chave: Autoria. Enunciado complexo. Sessão de autógrafos. Corporalidade. Assinatura.

\section{APRESENTAÇÃO}

A problemática estabelecida em torno da noção de autor parece estar longe de ser esgotada. À medida que vão surgindo materialidades distintas - sobretudo pelas mídias eletrônicas e virtuais, capazes de abrigar as mais diversas formas de expressão passíveis de autoria -, a questão legada por Foucault (2009) ressurge, principalmente na Linguística, para permanecer sem uma resposta satisfatória: afinal, o que é um autor?

O fato é que há, em uma sociedade centrada na escrita, como a nossa, certos discursos que necessitam da função-autor para se instituírem de tal forma e não de outra,

\footnotetext{
* Doutor em Estudos Linguísticos pela Universidade Federal de Minas Gerais. Bolsista CAPES de pósdoutorado no Programa de Pós-Graduação em Letras da Universidade Federal de Santa Maria, Rio Grande do Sul. E-mail: alvescosta.lp@gmail.com.

** Mestre em Letras e suas Interfaces pela Universidade Estadual do Centro-Oeste, Unicentro, Paraná; doutoranda em Letras na Universidade Federal de Santa Maria, Rio Grande do Sul. E-mail: lachovkimarilda@gmail.com.
} 
ou seja, discursos que só se fundamentam, atualmente, em torno da noção de autor, tal qual parece ter sido pensada por Foucault (2009). Desses discursos, a Literatura tem sido o carro-chefe na proposição de questões sobre a autoria, mas ela não é, de modo algum, o único discurso capaz de pôr em funcionamento nomes autorais. Podemos citar o Cinema, a Música, as Artes, a Ciência, os Quadrinhos, e possíveis outros, que COSTA (2016) chamou de discursos autoriais, "aqueles discursos para os quais a função-autor é fundamental, ou seja, em que o nome de Autor é o centro de uma instituição, sendo ele construído de maneira coletiva por meio de uma rede de aparelhos e com base em um arquivo." (COSTA, 2016, p. 69). Nos discursos autoriais, o nome de Autor, distinto de quaisquer nomes próprios, é indício de práticas muito específicas: ele manifesta, como o disse Foucault (2009), a ocorrência de um certo conjunto de discursos com um status igualmente distinto no interior de uma sociedade e de uma cultura.

Amparado por noções do arcabouço de Foucault (2008, 2009) em diálogo com pressupostos de Costa (2016), Orlandi (1987, 1998, 2005), Gregolin (2003, 2004), Pêcheux (2009) e Fraenkel (1992), este trabalho visa, em um primeiro momento, aproximar as noções de autor e enunciado, para, a partir daí, discutir a dupla dimensão do nome de autor, a saber: aquela que remete ao autor enquanto sujeito (quer dizer, o autor personificado ocupando uma posição-sujeito) e aquela que remete a um conjunto de regras de formulação de sentidos (quer dizer, o autor enunciado, um efeito de sentido para os discursos autoriais), correlato da obra, l'homme-et-l'œeuvre. Em seguida, em um segundo momento, discutiremos sobre algumas materialidades ínsitas desse enunciado em uma dédicace ${ }^{1}$ quadrinística - o nome, a obra, o corpo e o gesto da assinatura - e como elas fazem a autoria funcionar para os Quadrinhos.

\section{CONSIDERAÇÕES INICIAIS}

Na análise de Foucault (2009), vê-se que a emergência da função-autor no interior de certos discursos se deu, de fato, atrelada ao sujeito enquanto responsável por um produto textual, à medida que os discursos se tornaram transgressores. A origem do texto, o autor, passou a ser responsabilizado. Instaurou-se, a partir de então, um regime de propriedade dos textos. A função-autor, nesse viés, relacionou-se inicialmente ao sistema jurídico e institucional. No entanto, os direitos e deveres legais sobre um texto estariam longe de mostrar perfeitamente o funcionamento da autoria. O direito autoral é um fato demasiado atrelado ao sujeito empírico para permitir vislumbrar o potencial da problemática instaurada em torno da função-autor àquela época, entre os séculos XVIII e XIX.

$\mathrm{Na}$ Antiguidade, os textos eram colocados em circulação e possuíam valor por si mesmos, ainda que não estivessem ligados a nomes próprios com o estatuto de autor. A antiguidade desses textos, verdadeira ou suposta, garantia sua importância no sistema de produção no qual surgia. Atualmente, certos discursos não são mais aceitos sem que a

\footnotetext{
${ }^{1}$ No campo quadrinístico francófono, é comum a prática da dédicace - uma sessão de autógrafos - quando um autor de $\mathrm{BD}$ (bande dessinée) lança sua obra. E nos grandes eventos da área, são organizados stands de cada autor, mesmo que este não esteja lançando obra alguma.
} 
eles possam ser atribuídos nomes próprios autorais, sem que se pergunte de onde eles vêm, quem os escreveu, em que circunstâncias ou a partir de que projeto (FOUCAULT, 2009). Apesar desse questionamento, para Foucault (2009), a função-autor de um texto não pode ser atribuída espontaneamente a um indivíduo - e frisar isso direciona toda a análise.

A instauração da função-autor consiste em movimentar um conjunto de práticas complexas (e coletivas) que constroem uma instância ou posição-sujeito denominada autor, que funciona especificamente para um tipo de domínio social, linguístico, discursivo. Portanto, não se constrói uma instância de autor filosófico como a de um poeta, e nem a de um autor de romances no século XVIII como atualmente (FOUCAULT, 2009). Mais do que designar a existência daquele que escreve, a função-autor estabelece um nome em torno do qual delimita-se uma teia de discursos. É nesse sentido que podemos corroborar a observação de Gregolin (2003), na qual ela diz que o nome de autor "não transita do interior do discurso para o indivíduo real e exterior que o produziu, mas, de alguma maneira, bordeja os textos, recortando-os, delimitando-os." (GREGOLIN, 2003, p. 50). Dito de outro modo, as observações de Gregolin (2003) nos permitem compreender que a função-autor estabelece uma certa maneira de abordar os discursos de uma determinada área ou domínio social, que seu funcionamento tem sua razão para essa determinada área com suas práticas discursivas específicas (a função-autor se manifesta diferentemente nos Quadrinhos, no Cinema, na Literatura...), e que o indivíduo real/empírico, e exterior a esse domínio discursivo, pouco importa para o funcionamento da função-autor.

Uma vez que é ressaltado que a função-autor não está no indivíduo (mas sim nos discursos), parece importante tentar contornar a hegemonia do sujeito sobre ela. A busca do gesto autoral, das marcas de estilo, da genialidade, enfim, da subjetividade do autor em textos de natureza diversa como tentativa de definir a autoria não faz mais do que inserir a função-autor em um dispositivo comunicacional, dando à pessoa do autor uma função que não é dela, mas sim do nome que ela porta. Do ponto de vista que adotamos, esse gesto autoral, efetivado por um sujeito em posição de autor, pode ser entendido como apenas uma evidência de uma prática de escrita passível de autoria, já que a criação de uma obra pode carregar a ilusão de ser o sujeito a sua origem e seu fim.

Tal postura tem feito surgir reflexões sobre a função-autor em textos ordinários, efêmeros, que não podem suportar o estatuto de opus (do latim, obra), como redações escolares, confissões em blogs ou redes sociais, poemas nunca publicados, etc. Essa autoria marcada exclusivamente pela presença de um sujeito em um texto qualquer na medida em que é tido como responsável pela escrita não aponta para um opus, não traz o Autor como correlato de uma Obra. Não pode haver aí, então, uma função-autor, exercida por um nome de Autor que perdure indiferentemente do(s) sujeito(s) que escreveu(ram) o texto. A autoria presente aí não seria mais do que uma responsabilidade efêmera pelo texto.

Pode-se supor que a pergunta sobre o que é um autor tem sido respondida como se fosse sobre quem é o autor, na medida em que se busca uma resposta focando a origem ou propriedade dos textos (a questão dos direitos autorais é centrada nisso, por exemplo). Mas se pensarmos o nome de autor com uma função na formação de certos discursos, que 
função seria essa, senão mostrar que ali, num dado domínio, acontece um fenômeno discursivo que é a autoria, correlacionando autores e obras? O que seria preciso existir e acontecer para que um nome fosse mais do que um nome de alguém, mas sim um nome de Autor, ainda que fosse um pseudônimo? "Se o pseudônimo [ou nome de Autor] faz convergir referente e significado até se tornar um substituto do sujeito, não faria ele desaparecer este último quando ele se confunde com o discurso?"2 (CISLARU, 2009, p. 56). O nome de Autor está além da persona do autor. Por esse viés, a convergência entre nome autoral e discurso se operaria via um simulacro de apagamento do sujeito. Mas podemos tratar desse apagamento do sujeito empírico em outra perspectiva também.

Orlandi (2005), em seus estudos, aponta para a noção de autor ou efeito-autor deslocando a noção posta por Foucault (2009), e afirma que um texto (enquanto obra) é sempre produzido por diversas mãos. Texto, no sentido que Orlandi (2005) adota, não se refere apenas ao gesto da escrita, mas compreende as mais diversas produções que pressupõem um autor; o texto, enquanto "peça", funciona diferentemente em condições específicas de produção. O texto é um objeto simbólico, logo, não é só um objeto empírico, mas um espaço de circulação e produção de sentidos. Nesse sentido, a autora coloca uma questão crucial para sua concepção de autoria, já que, na Análise de Discurso à qual se filia, é preciso intervir a leitura e a interpretação. A obra, por este viés, é espaço de uma correlação entre sujeito/autor; discurso/texto (ORLANDI, 2005). Apreender essas relações sob o viés da autora é entender que "o sujeito só se faz autor se o que ele produz for interpretável. Ele inscreve sua formulação no interdiscurso, ele historiciza seu dizer." (ORLANDI, 2005, p. 70). Podemos dizer que o efeito de unidade da obra permite a produção (ilusória) de fechamento e unidade dela, no entanto, esse "efeito discursivo deriva do princípio de autoria", como afirma Orlandi (2005, p. 75). Portanto, a autoria seria uma função discursiva que regula a entrada do sujeito na ordem do dizer, sua tomada de posição dentro de determinadas condições estabelecidas e condicionadas pelas formações discursivas (e ideológicas, se por uma perspectiva pêcheutiana).

Para Foucault (2008) a noção de formação discursiva está ligada à unidade e dispersão, e, como unidade, integra e compõe um dado conjunto de enunciados inscritos sob um índice de repetibilidade. No entanto, mesmo repetíveis os objetos que estruturam os enunciados, estes funcionam como únicos, uma vez que sobre eles atuam as diferenças, entendendo o enunciado como nunca repetível, mas ligado aos modos de produção e circulação dos saberes que os inscrevem na historicidade. Logo, segundo Foucault (2008), sempre que, na descrição, houver,

\footnotetext{
[...] entre um certo número de enunciados, semelhante sistema de dispersão, e no caso em que entre os objetos, os tipos de enunciação, os conceitos, as escolhas temáticas, se puder definir uma regularidade (uma ordem, correlações, posições e funcionamentos, transformações), diremos, por convenção, que se trata de uma formação discursiva. (FOUCAULT, 2008, p. 43, grifos do autor).
}

\footnotetext{
${ }^{2}$ Si le pseudonyme [...] fait converger référent et signifié jusqu'à devenir un substitut du sujet, ne fait-il pas disparaître ce dernier lorsqu'il se confond avec le discours ? (A tradução do francês é de nossa responsabilidade).
} 
Já para Pêcheux (2009, p. 147), a formação discursiva é "aquilo que, numa formação ideológica dada, isto é, a partir de uma posição dada numa conjuntura dada, determinada pelo estado de luta de classes, determina o que pode e deve ser dito [...]", sendo que as formações discursivas, segundo o autor, "representam 'na linguagem' as formações ideológicas que lhes são correspondentes”. (PÊCHEUX, 2009, p. 147). Podemos dizer que que a formação discursiva orienta e regula não só o que pode e deve ser dito, mas também os modos de produção, circulação e legitimação dos discursos em um campo, ou ainda, como postula Pêcheux (2009, p. 148-149), "dissimula, pela transparência do sentido que nela se constitui, sua dependência ao 'todo complexo com dominante' das formações discursivas", ou seja, o interdiscurso, submetido às leis de "desigualdade-contradição-subordinação", próprio das formações ideológicas. É relendo Pêcheux que Orlandi (1998, p. 58), afirma ser a formação discursiva "o lugar de constituição do sentido e da identificação do sujeito".

Logo, uma obra, pelo viés discursivo, não é definida como um produto, mas como materialidade sempre em processo, sempre aberta ao simbólico e ao político, à interferência de outros sujeitos - leitores e mediadores - coletivamente. Se estamos tomando Obra e Autor como correlacionados/correlatos, é mister um esforço teórico para apreender a autoria como produção coletiva em um campo.

\section{O AUTOR COMO ENUNCIADO COMPLEXO}

De acordo com Lecolle et al. (2009), o sentido dos nomes próprios está estreitamente ligado às diferentes ancoragens sociais dos discursos: histórica, geográfica, sociológica, literária etc. O nome próprio tem, assim, uma função pontual numa dada formação discursiva. Mas, afinal, quando é que um nome próprio adquire historicidade? Quando e como ele passa a ser ponto central de práticas e discursos de uma certa comunidade, de certos registros, de certos investimentos simbólicos? Colocar em questão o nome próprio, e, mais especificamente, o nome de Autor, mobiliza, de modo inevitável, sua relação com o social e com o histórico, pois, como todo nome próprio, o nome de Autor tem uma função, o que sinaliza, para sua posição sujeito-autor, um sujeito duplamente afetado, pelo real da língua e da história.

\footnotetext{
Sendo a autoria a função mais afetada pelo contato com o social e as coerções, ela está mais submetida às regras das instituições e nela são mais visíveis os procedimentos disciplinares. [...] Não basta falar para ser autor. A assunção da autoria implica uma inserção do sujeito na cultura, uma posição dele no contexto histórico-social. Aprender a se representar como autor é assumir, diante das instâncias institucionais, esse papel social na sua relação com a linguagem [...]. (ORLANDI, 2005, p. 75-76).
}

O excerto acima aponta para a inscrição do sujeito nas práticas sociais efetivas, na história e no político, como divisão tanto de sentidos quanto do sujeito, que, em sua ilusão de origem do dizer, "esquece" que não domina nem os sentidos, nem o que diz, sendo, portanto, também ele, o sujeito, um efeito, e por isso assume uma posição, filia-se e inscreve-se em formações discursivas para que assim, possa entrar na ordem do dizer. 
Contudo, o nome de Autor que nos interessa habita não só no sujeito; ele é, ao mesmo tempo, uma construção social, coletiva, ideológica: um efeito de sentido no interior de certos discursos nos quais se funda e que ajuda a fundar, na sua constituição na/pela linguagem. Como se vê, esse raciocínio nos permite aproximar a noção de função-autor daquela de efeito-autor, proposta por Orlandi (2005), e de enunciado complexo, adiante, de Costa (2016).

Muitos autores adotam pseudônimos bem distintos (por exemplo, Taumaturgo Borges tem por pseudônimo Mike Deodato, famoso quadrinista). Mesmo que um nome de Autor seja igual ao nome civil da persona, ele será um pseudônimo à medida que a distância entre a persona e o Autor se intensificar pelo investimento simbólico a esse nome. Neste caso, não se trataria mais de um nome falso, mas sim de uma pessoa qualquer que não consegue mais portar o seu nome verdadeiro, civil, a não ser em condições sociodiscursivas específicas, restritas ou até mesmo obrigatórias.

Os nomes próprios autorais exercem mais do que a função de especificar seus portadores. Eles são também um modo de agregar significados dispersos sob um só termo. É nesse sentido que nos encontramos com a concepção de enunciado de Foucault (2008):

\begin{abstract}
Um enunciado não tem diante de si (e numa espécie de conversa) um correlato - ou uma ausência de correlato, assim como uma proposição tem um referente (ou não), ou como um nome próprio designa um indivíduo (ou ninguém). Está antes ligado a um "referencial" que não é constituído de "coisas", de "fatos", de "realidades", ou de "seres", mas de leis de possibilidade, de regras de existência para os objetos que aí se encontram nomeados, designados ou descritos, para as relações que aí se encontram afirmadas ou negadas. $\mathrm{O}$ referencial do enunciado forma o lugar, a condição, o campo de emergência, a instância de diferenciação dos indivíduos ou dos objetos, dos estados de coisas e das relações que são postas em jogo pelo próprio enunciado; define as possibilidades de aparecimento e de delimitação do que dá à frase seu sentido, à proposição seu valor de verdade. (FOUCAULT, 2008, p. 103).
\end{abstract}

Como um conjunto de regras de possibilidades para os discursos, os enunciados se formam por meio de regulações dentro de formações discursivas. Lembremos que Foucault (2008) define a formação discursiva como um conjunto de enunciados articulados por um sistema de dispersão e de regularidade, e que, deslocando-se para Pêcheux (2009) e Orlandi (1998), as formações discursivas são o que "determinam o que pode e deve ser dito [...] a partir de uma posição dada numa conjuntura" (PÊCHEUX; FUCHS, 1997, p. 166).

A cada enunciação, essas regras de existência para um determinado objeto transformam-se, acumulam-se, opõem-se, enfim, tornam-se outras devido ao caráter histórico da enunciação e do enunciado. A noção de enunciado é particularmente importante neste trabalho. Para Foucault (2008), o enunciado é um acontecimento: diferente, a enunciados que o precedem e o seguem. (FOUCAULT, 2008, p. 31-32). 
Ainda sobre o enunciado, Orlandi (1998) aponta para a relação texto/discurso/enunciado, concebendo o texto como unidade de análise, mas não sendo por si só a unidade de construção do discurso, ou seja, ainda segundo Orlandi (1998), se a unidade de construção do discurso é o enunciado, ele não o é isoladamente, mas deve ser referido ao texto para poder ser apreendido no processo de construção do discurso. Logo, o texto não é um objeto empírico, com início, meio e fim, mas objeto simbólico, aberto e múltiplo, uma vez que outros textos o margeiam, o compõe e o constituem. Há, portanto, um determinado índice de repetibilidade, mas também de dispersão, de divisão, movimentos que desdobram-se na historicidade e retornam pelo funcionamento da memória.

Um enunciado, portanto, pode se repetir em materialidades diferentes. Por exemplo, uma narrativa romântica pode aparecer materializada em várias edições distintas, com línguas diferentes e em épocas diferentes, mas será o mesmo enunciado, ao menos até certo limite de inovação. Neste caso, há um esforço silencioso, coletivo, não pensado, naturalizado em preservar o enunciado a despeito das múltiplas ocorrências em materialidades outras. Mas pode ocorrer que esse esforço não seja importante, pode ocorrer de os sujeitos enunciarem nos entremeios deixados pela dispersão de um enunciado. Neste caso, as várias materialidades fazem retomar o enunciado através da memória, atualizando os seus sentidos, agregando ou silenciando sentidos outros (aludimos às adaptações literárias, por exemplo). A descrição almejada do enunciado "deve ser capaz de se mover com o seguinte paradoxo: o enunciado é ao mesmo tempo não visível e não escondido". (ORLANDI, 1987, p. 17).

A autoria, portanto, é também um efeito, pois sinaliza para uma tomada de posição do sujeito, que atesta para a ilusão de autonomia, e que pelo efeito de unidade pode conduzir ao nome de autor como produto, mas "o discurso não é um conjunto de textos, é uma prática" (ORLANDI, 1998, p. 56). Dito isso, podemos considerar discursivamente o nome de Autor como processo, logo, é móvel, não homogêneo, não uno, não mero produto, mas funcionamento. Enquanto processo discursivo, é sempre um efeito tendo em vista que não condiz com a busca pela gênese, pela autoria como princípio de autonomia e responsabilidade do autor (sujeito empírico), não é só um "projeto totalizante de um sujeito, projeto este que se converte em autor”. (ORLANDI, 1998, p. 56). E o que se diz desse nome, os sentidos produzidos acerca de sua produção, pode ser vasto ou não, dependendo do quão memorável é o Autor. E como enunciado, os nomes de Autor, nos termos de Gregolin (2004, p. 31): "agenciam a memória, constroem a história, projetamse do passado ao futuro", e diríamos, constroem diferentes temporalidades, permitem o deslize de sentidos produzidos sobre o Autor, constituindo-o na sua heterogeneidade. Mas, nem tudo se pode dizer. Os sentidos e os sujeitos estão, como já destacamos, inscritos em diferentes formações discursivas.

A partir da concepção foucaultiana de enunciado, COSTA (2016) desenvolveu o conceito de enunciado complexo: aquele tipo de enunciado que assume a forma de um nome próprio, cujo funcionamento consiste em permitir e regular os dizeres de uma dada comunidade de fala (para a qual esse nome tem importância social, teórica, ideológica), ainda que sejam dizeres contraditórios, de modo que as partes, os dizeres, sejam relativamente autônomos uns em relação aos outros, mas que sejam também responsáveis 
pela construção dos sentidos do todo. O enunciado complexo assume, como indica o nome, a forma de um complexo: um todo divisível, mas cujas partes, ainda que visem excluir umas às outras, delas precisam concomitantemente para formar o todo. Para manter essa ilusão de unicidade, o enunciado complexo precisa se abrigar sob um nome próprio. Esse nome, que seria, em qualquer enunciação, naturalmente um enunciado, assume a função de enunciado complexo se preencher alguns requisitos, dentre os quais, o de indexar discursos, enunciados outros, funcionando como nome de Autor.

Assim, o nome de Autor seria, segundo COSTA (2016), um enunciado complexo: fala-se de William Shakespeare, mas tudo o que é dito de importante sobre ele é regulado institucionalmente; do mesmo modo, Shakespeare permeia o imaginário de alguns estudiosos, pergunta-se "quem foi Shakespeare", e os estudos de sua Obra, bem como os de sua biografia, respondem "o que foi Shakespeare". Tem-se, assim, que o nome "Shakespeare" remete ao mesmo tempo a alguém que foi autor e a um enunciado com função de autor, logo, o nome "Shakespeare" funciona como índex para uma série de discursos que abrigam e constituem tanto a obra, quanto o autor.

Diremos, então, que a instância autor atrelada unicamente a um dispositivo de comunicação não é a mesma categoria Autor que é tomada como índice e correlato da Obra. A primeira corresponde a um lugar discursivo atribuído, grosso modo, ao sujeitocomunicante/sujeito-enunciador. A segunda, que é uma categoria construída coletivamente (e sempre em contrução) por meio de todo um aparato instituído discursivamente, é um enunciado. Quando se fala do autor enquanto instância produtora de sentidos, inclui-se aí, direta ou indiretamente, uma instância coprodutora de sentidos, que é a do leitor. Mas quando se fala do Autor enquanto correlato do Opus, não se situa do outro lado uma categoria Leitor que seja sua contraparte, porque não se trata de categorias de sujeito, ou de posições de sujeitos. Esse Autor do qual estamos fazendo distinção aqui não é algo presente no dispositivo comunicacional como instância de sujeito, mas sim produto e processo desse mesmo dispositivo em que há uma instância que também é chamada "autor". Trata-se do "Autor" como enunciado, e não como enunciador.

Ao enunciar sua obra, o autor enuncia também a si mesmo, o seu nome e em seu nome. Ele diz, num só tempo e num só gesto complexo, a "Obra” e (se) diz "Autor" (esse dizer é mais do que um falar sobre, é todo um enunciar e os aspectos pragmáticos que isso implicaria). Sua atividade de tomar a palavra não é uma enunciação corriqueira, efêmera, mas uma enunciação que lega para a posteridade enunciados sobre os quais e por meio dos quais toda uma categoria muito específica de discurso se funda - a dos discursos autoriais, que adquirem forma pela instauração progressiva de Autores e Obras. Mas, tal como disse o próprio Foucault (2008), deixaremos de lado...

[...] a análise histórico-sociológica do personagem do autor. Como o autor se individualizou em uma cultura como a nossa, que estatuto lhe foi dado, a partir de que momento, por exemplo, pôs-se a fazer pesquisas de autenticidade e de atribuição, em que sistema de valorização o autor foi acolhido, em que momento se começou a contar a vida não mais dos heróis, mas dos autores, como se instaurou essa categoria fundamental da crítica "o homeme-a-obra", tudo isso certamente mereceria ser analisado. (FOUCAULT, 2009, p. 267). 
O traço entre "o-homem-e-a-obra" é sintomático de uma percepção acurada por parte do filósofo francês de que não se trata, de um lado, do autor, do homem, e do outro, do texto, da obra, mas sim de um amálgama dos dois. Não se trata da união dos elementos "o sujeito que enuncia" e "a obra enunciada", mas sim de um elemento outro, à parte, nem autor/sujeito, nem obra/texto, mas que ainda assim aponta para ambos, para o portador do nome de Autor e para o produto de sua autoria. Os hifens significam uma só palavra, uma só coisa, substantivada, embora ainda abstrata, e tal expressão conota um aspecto particular na produção de sentidos dos discursos autoriais: há um tipo de enunciado tão complexo que não se permite notar na cisão entre autor e obra, pois tal enunciado é, de fato, produzido no autor e na obra. Em l'homme-et-l'oeuvre, como traz o original, reside essa ambiguidade necessária para a existência de autores e obras da maneira que ocorre (um funcionamento muito menos problemático na Literatura, na Filosofia, e em discursos autoriais em que a coautoria é uma rara exceção, do que em discursos como a Música ou os Quadrinhos).

Assim, nomes de Autor como Giraud ou Moebius podem ter a mesma persona responsável por eles. De fato, Giraud se consagrou igualmente com o pseudônimo Moebius. Outro exemplo é o Autor Claude Guylouis, que nada mais é do que um pseudônimo composto pela persona de três autores: Claude Klotz, Jean-Louis Robert e Guy Vidal. Juntos, e sob a assinatura de Guylouis, foram autores de diversas histórias do personagem Lucky Luke. Guylouis também assinou com Emmanuel Boëm uma banda desenhada intitulada Sam et Léna (1992), pela editora Dargaud. Porém, Klotz já tinha um outro pseudônimo solo: Patrick Cauvin. Tanto Klotz quanto Cauvin tiveram uma produção autoral vasta, incluindo nela outras peças além de bandas desenhadas.

E o que dizer, também, do caso de autores que se escondem sob um nome feminino? $\mathrm{Ou}$, melhor ainda, sobre um caso bem particular: o que dizer $d o$ Laerte/da Laerte? O nome de Autor, enquanto enunciado, não tem gênero masculino ou feminino como ocorre com as pessoas em seu estatuto civil e/ou biológico. Seu funcionamento discursivo - sua função-autor - independe do gênero, e apenas sua ancoragem à dimensão personificada do Autor faz precisar gênero. Ainda que o autor mudasse de sexo, seu nome de Autor permaneceria indiferente em sua função.

A trajetória de Laerte no campo quadrinístico é polêmica, tanto por suas obras, quanto por sua persona. Sua carreira começou em 1985, com o lançamento de seu livro de charges, desenhos e cartuns, $O$ tamanho da coisa. Nessa época, sua persona ainda assinava como um autor. Mas, recentemente, sua persona assumiu outro papel genérico. $\mathrm{O}$ autor passou por um processo de mudança cívico-estatutária para autora (que, em alguns casos, inclui mudança fenotípica), daí o nome transgênero. Em entrevista, quando questionada sobre sua sexualidade, Laerte Coutinho (2015, web) disse: "Escolhi Sonia porque pareceu, literalmente, a minha cara: 'olhei no espelho e me chamei de Sônia", e acrescentou: "Gosto de Laerte, tenho uma vida inteira com ele, nunca tive aversão por ele ou por outros aspectos da minha vida em masculino.” (COUTINHO, 2015, web). Inferimos, desta declaração de Laerte, que sua posição enquanto Autor não foi modificada por sua opção e mudança de gênero, o que nos permite pautar mais eficientemente o exposto acima - não é, de fato, nem só o nome, nem só a persona, nem só a obra que designa e faz funcionar a noção de Autor: toda essa rede de discursos construídos nos/pelos enunciados que o determinam e o nomeiam o particularizam entre outro(a)s Laertes: regularidade e dispersão. 
O personagem Hugo, criado em 1995, como uma espécie de alter ego do autor Laerte, também sofreu mudança, a partir de 2005, quando Laerte iniciou a prática do crossdresser. Mas, ao contrário de Laerte, que não assumiu pseudônimo, o personagem passou a se chamar também Muriel: "É como se a vida tivesse me levado a essa circunstância e, quando eu me vi, percebi que aquilo representava uma busca pra mim. Foi mais ou menos isso que senti. Quando vi, comecei a fazer tiras do Hugo virando a Muriel” (COUTINHO, 2010, web). A obra de Laerte expõe, assim, uma visível identificação com sua trajetória de posicionamento no campo discursivo quadrinístico (COSTA, 2016). Não se trata, então, de dois Autores diferentes: analisar o conjunto da Obra de Laerte significaria levar em conta a trajetória de sua persona, que mudou de gênero, mas a compilação de sua Obra estaria unicamente sob seu nome de Autor, indiferente a seu estatuto atual de autora. Ainda que o nome pareça sofrer uma cisão estatutária no nível social, o Laerte ou a Laerte continua a fazer referência a um Autor enquanto enunciado complexo.

E no caso dos autores mortos, muitas vezes fala-se deles como se estivessem presentes no mundo: "Por que tal autor é tão bom? Ele é um autor transgressor". Fala-se como se suas personas ainda fossem agentes no mundo, como se eles mesmos ainda gerissem seus posicionamentos no campo. Mas eles não existem mais como agentes civis. O que resta são seus nomes. E nomes estão mais para enunciados do que para sujeitos, muito embora sejam constitutivos deles. Talvez, insiste-se na personificação desse enunciado, que se resume ao nome do Autor, por ser essa sua natureza, por ele ter esse funcionamento além daquele de indexar ' $n$ ' obras.

O fato de a correspondência e os rascunhos de um Autor serem passíveis de publicação não faz deles um elemento de seu Opus. Primeiro, porque esses textos periféricos só foram publicados por serem de tal ou tal Autor - é o seu nome que os legitima para a publicação. Segundo, porque esses textos, que, de fato, auxiliam na construção da imagem de Autor (e alguns até na leitura das obras), não foram, a princípio, realizados para serem constituintes do Opus. Ainda que o fossem, ou melhor, ainda que o passassem a ser, essas correspondências ou esses esboços, por exemplo, sofreram considerável mudança em seu estatuto de gênero: esses textos periféricos em relação à Obra deixaram de atender à função para a qual foram originalmente designados.

No Discurso Quadrinístico, é comum a editora publicar um sketch book com os estudos sobre um determinado personagem por parte de um desenhista. Os rascunhos são compilados e recebem um tratamento editorial próprio, mas não são histórias em quadrinhos: eles, por si só, não são capazes de fazer um autor persona ou autor-ator ascender ao status de Autor. Se não fosse pelo nome já consolidado do Autor, eles seriam esboços sem nome, identificáveis, talvez, pelo estilo pessoal, mas contra isso sempre poderia haver imitadores.

\section{AS MATERIALIDADES DO ENUNCIADO}

Reduzir os estudos sobre ofuncionamento da autoria (que é também ofuncionamento de um nome próprio no contexto de uma prática institucional específica) ao entorno pragmático dos direitos autorais seria relegar à periferia toda a importância que a Renascença estabeleceu para o papel do artista e das obras no cenário cultural mundial. Como afirmou 
Bagnariol (2004), foi na Renascença que a concepção de artista e obra de arte que conhecemos hoje começou a se consolidar, e a assinatura do autor acabou por se tornar parte fundamental da obra e do processo de reconhecimento do artista.

É verdade que faltaria ainda mais de dois séculos para que a autoria se tornasse uma questão jurídica, mas é fato que, bem antes disso, o nome de um artista já estava sendo convencionalmente imbuído de significados e valores a ponto de determinar toda sorte de práticas institucionais em torno dele. Esses sujeitos já se beneficiavam do reconhecimento estatutário resumido em seu nome. Bem antes de indicar uma propriedade, a assinatura (que é um sinal específico), assinalava a qualidade de uma peça que poderia ser ajuntada a outras de igual status quo. Nesta seção, abordamos algumas características da assinatura no contexto dos Quadrinhos enquanto discurso autorial, e, mais especificamente, em uma sessão de autógrafos.

Assinar é uma prática comum a muitas pessoas, mas as condições que as levam a fazê-lo são regidas por regras tão específicas que podem modificar tanto o signatário quanto a própria situação. Como disse Fraenkel (1992), assinar é um ato que não é nem estritamente escrever e nem estritamente desenhar, mas um meio-termo entre os dois: o nome próprio fornece a base linguística, o alfabeto e as formas das letras, mas a mão deve estar treinada a transformar esses elementos em um material gráfico personalizado e convencional, que tem um pouco de escrita e de imagem.

\begin{abstract}
A assinatura é o vestígio de um verdadeiro sistema de signos de identidade do qual se desprendeu no séc. XVI e, desde então, persiste sozinha como um signo isolado. Além disso, ela pertence a esses signos chamados de "validação" cuja função é transformar algum documento escrito em ato jurídico. É, então, no interior de um universo de signos e de práticas que se deve inseri-la se queremos dar ao signo sua dimensão verdadeira. ${ }^{3}$ (FRAENKEL, 1992, p. 7)
\end{abstract}

Nos discursos autoriais, a assinatura é um signo que apresenta três importantes funções, a saber, a de individualização do signatário (marcar a sua presença e singularidade), a de sua autorialização (reconhecer o seu nome de Autor e autoridade enunciativa) e a de validação (validar esse processo de instituição de si e de sua obra). Essas funções são interdependentes, cada uma se nutre do processo que a outra desencadeia.

Enquanto signo de individualização, a assinatura é única, intransferível e inalienável. A assinatura não assinala apenas o autor, uma vez que o nome próprio citado, por exemplo, numa biografia, numa entrevista ou na capa de uma obra, já cumpriria esse papel. Por meio dela, certifica-se a presença consciente de um indivíduo atrelado a práticas sociodiscursivas exclusivas, sua corporalidade enquanto autor.

Mas a assinatura é um signo que faz referência também à singularidade do autor, da persona que assinou/assinalou sua marca - a assinatura não se limita ao nome

\footnotetext{
${ }^{3}$ La signature est le vestige d'un véritable système de signes d'identité dont elle se détache au XVIe siècle et, dès lors, persiste seule, tel un signe isolé. En outre, elle appartient à ces signes dits de « validation » dont la fonction est de transformer un quelconque document écrit en acte juridique. C'est donc à l'intérieur d'un univers de signes et de pratiques qu'il faut l'insérer si l'on veut rendre au signe sa dimension réelle.
} 
propriamente dito. De fato, alguns desenhistas têm uma marca tão estilizada para a assinatura, que ela difere em tudo de caracteres linguísticos. E não é raro encontrar autores que, literalmente, desenham a sua assinatura. A enunciação gráfica, que traz com ela um efeito-assinatura, de acordo com Stefanelli (2012), é também uma impressão-assinatura, um traço idiossincrático que remonta à relação existente entre a subjetividade do autor e o corpo treinado do desenhista (STEFANELLI, 2012).

\section{Figura 1 - Assinaturas de autores}

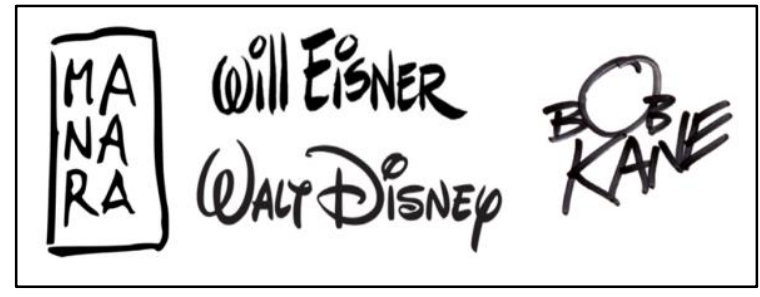

Fonte: Costa (2016). Acervo pessoal.

Diferentemente do que ocorre nas esferas jurídicas, comerciais e/ou políticas, em que o signatário pode subscrever seus poderes, nas dédicaces não se pode dar um autógrafo por procuração. Não se trata, portanto, de qualquer signatário, mas da persona de um Autor. Trata-se de um sujeito previamente reconhecido e individualizado por uma função: a de ser porta-voz de um nome de Autor, sendo esse o segundo elemento para o qual aponta o signo da assinatura.

Com a função de autorização (ou, no caso dos discursos autoriais, de autorialização, conforme COSTA (2016)), a assinatura dá ao objeto assinado um nome próprio por ele responsável e/ou possuidor de certo status quo dentro de um contexto, de uma convenção. Amparada pela instituição discursiva, a persona que autografa uma obra não o faz em seu nome (embora faça o seu nome), antes, ela autografa em nome dessa mesma instituição da qual é porta-voz. Numa sessão de autógrafos, o autor utiliza o seu pseudônimo ou nome de Autor, e não o seu nome civil (Walt Disney, e não Walter Elias Disney, por exemplo).

O terceiro elemento para o qual a assinatura aponta é a obra enquanto Obra. A perfomatividade instituída no ato de autografar uma obra só se fundamenta em razão dessa última. Essa não é uma constatação tão óbvia quanto parece, pois o que está em jogo não é puramente a existência da obra para que se possa autografá-la, mas sim um ritual de dupla legitimação cujo instrumento é a assinatura. Ou seja, o autógrafo não existe apenas porque a obra existe, mas ele existe para que a obra reafirme sua existência.

A partir do binômio l'homme-et-l'œuvre, vê-se que a performance da sessão de autógrafos consagra também o Autor como enunciado (e não apenas como sujeito). A assinatura, em relação à obra, tem, assim, a função de validar o objeto assinado - o quadrinho, o romance, a pintura - como Obra, pois porta um nome de Autor. Ao mesmo tempo, ela valida o Autor em sua dimensão personificada, pois só a persona pode autografar sua Obra. 
Dos muitos ritos institucionais nos quais a assinatura é fundamental (o casamento civil, o contrato de trabalho, o decreto de Lei, por exemplo), a sessão de autógrafos é um daqueles em que a própria assinatura é também uma meta, e não um estatuto ou ações ulteriores dependentes e/ou consequentes dela. Ela é ao mesmo tempo o ato ("eu autografo") e o resultado do ato ("o autógrafo").

\begin{abstract}
A presença de uma assinatura pode modificar radicalmente a natureza de um ato, é ela que lhe confere esta autenticidade sem a qual a escrita restaria como letra morta. Esse poder, a assinatura o deve à sua função principal, aquela de servir de signo de validação. ${ }^{4}$ (FRAENKEL, 1992, p. 18).
\end{abstract}

Cada situação de uso da assinatura confere-lhe um estatuto próprio, que transita entre a identidade e a autoridade. $\mathrm{O}$ uso da assinatura está intimamente ligado à prática em questão, às suas condições de produção e de eficácia. A assinatura de um contrato de edição, por exemplo, tem um valor diferente daquela empregada em uma sessão de autógrafos - a primeira situação pode exigir que a persona assine com o seu nome próprio de registro civil, já a segunda exige o nome de Autor, comumente na forma de pseudônimo. Bill Watterson, em uma carta ao editor Bill Yates, da King Features, assinou com o seu nome civil, William Boyd Watterson.

Figura 2 - Assinatura civil de Bill Watterson

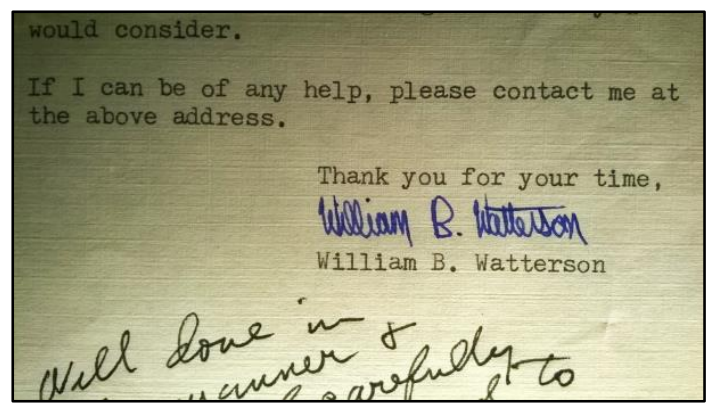

Fonte: Costa (2016). Acervo pessoal.

Para os discursos autoriais, a prática da assinatura do nome de Autor está amparada por toda uma instituição discursiva, quer dizer, a prática do autógrafo é tão mais prevista e esperada sem estranhamento quanto maior for o reconhecimento do capital simbólico de tal instituição. A assinatura apresenta-se, assim, nessa situação amplamente performática, como um elemento constituído e constituinte da autorialidade, e "se ela caracteriza o signatário, revela igualmente uma certa concepção social da identidade do indivíduo"5 (FRAENKEL, 1992, p. 8). Uma sessão de autógrafos é um rito que faz comprovar a existência da persona do Autor, a distinção de seu nome em relação a um nome qualquer, e, não menos importante, a existência de uma Obra. A partir do nome próprio de Autor, situado no tempo e no espaço, a escrita autorial adquire:

\footnotetext{
${ }^{4}$ La présence d'une signature peut modifier radicalement la nature d'un acte, c'est elle qui lui confère cette authenticité sans laquelle l'écrit resterait lettre morte. Ce pouvoir, la signature le doit à sa fonction principale, celle de servir de signe de validation.

5 [...] la signature, si elle caractérise le signataire, révèle également une certaine conception sociale de l'identité de l'individu [...].
} 
[...] a corporalidade de um "autor" e, com ele, a representação estética de um estilo, de uma "obra", de uma "autoridade" sobre o discurso aí enunciado. A atribuição de uma assinatura de autoria a um texto constitui a escrita como expressão de uma individualidade que fundamenta a autenticidade da obra, atribuindo ao autor a ideia de invenção individual e criação original. (GREGOLIN, 2003, p. 50).

O nome de Autor é a base da prática da dédicace, e é em torno dele que esse ato adquire o seu valor simbólico. Esse nome já é resultado de investimento prévio por parte de toda a instituição discursiva. A assinatura, quando faz referência a esse nome e confirma sua corporalidade (pois ela deve ser uma ação de próprio punho), legitima a persona como sujeito dessa instituição, o quadrinista em sua função. E quando ela faz referência, ao mesmo tempo, ao nome e à Obra, ela legitima o Autor como um enunciado construído nessa instituição. Essa distinção pode ser sintetiza pelo diagrama a seguir:

Diagrama 1 - Funções da assinatura no discurso autorial

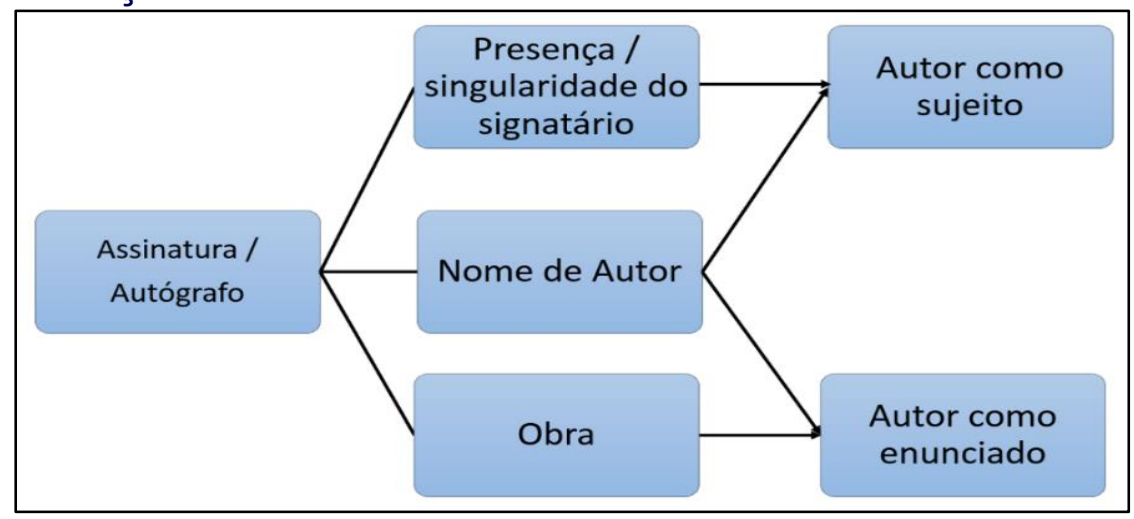

Fonte: Costa (2016)

Nota-se que a assinatura em uma dédicace opera, ao mesmo tempo, a cisão e a união do sujeito, do nome, do corpo e da obra. Mas como não há razão de existir uma dédicace sem o dedicatário, esse assume um papel tão importante como o do autor nesse tipo de discurso. Podemos dizer que nesse ritual intervém a dupla relação exterioridade/interioridade que constitui não só a obra (enquanto texto), nem só a persona (enquanto sujeito), mas também a Obra e o Autor, instituindo-se o homem-obra na(s) materialidade(s) do enunciado. Se tratamos da materialidade do enunciado, é preciso que pontuemos também a materialidade do sujeito, uma vez que sentido(s) e sujeito(s) são, por sua vez, indissociáveis (MALDIDIER, 2003). Nesse sentido, trabalhamos, mesmo que sucintamente, a noção de corpo atrelada ao sujeito, aos sentidos e ao próprio ato de assinatura na dédicace.

Pensar o corpo do sujeito implica compreendê-lo como lugar de significação, de produção de sentidos, não sendo apenas um invólucro do sujeito, mas parte de sua constituição, na medida em que não há como desvinculá-lo do social. É do corpo e no corpo que se estabelecem as transferências e deslocamentos de sentidos, é também por ele que o sujeito se inscreve no social, no político, significando e sendo significado. No ritual de assinatura, portanto, o corpo do autor, em sua materialidade enquanto sujeito inserido em determinadas condições, é lugar de interpretação, lugar de legitimação e circulação de enunciados. 
O sujeito no/do discurso é um sujeito duplo: ele está no discurso, pois a linguagem em sua não transparência e não completude pode ser tomada como um ambiente de interação. Em seu interior, o sujeito se comporta de tal ou tal maneira. Mas ele é também o sujeito do discurso, pois a linguagem tem os seus conteúdos, os seus efeitos de sentido, e, pela produção desses efeitos, o sujeito é um deles. É parte constitutiva dessa ilusória totalidade significante e significada. O sujeito é parte do sentido também.

A sessão de autógrafos reforça a existência da categoria de autor - ou melhor, põe em funcionamento o nome de Autor e dá a ele visibilidade e corporalidade. A sessão de autógrafos possibilita ver o Autor em funcionamento em várias materialidades: o Autor enquanto formulação discursiva, ou melhor, como um enunciado, materializa-se no nome de Autor (que pode ser um pseudônimo), na Obra em si, na persona do autor (em sua corporalidade, podendo ser constituída por mais de um corpo, como no caso dos pseudônimos de coautoria) e no gesto do autógrafo (que só pode ser executado pela persona do autor e que reforça o nome de Autor como outra materialidade). O corpo do autor, o nome grafado, a obra reconhecida, o gesto da assinatura.

$\mathrm{Na}$ sessão de autógrafos, o corpo do autor cumpre a exigência de verdade. Ele se torna uma materialidade significante, sua presença pode ser interpretada. Assim, o corpo, como construção simbólica, é textualizado pelos sujeitos envolvidos na dédicace, que significam-se mutuamente, inscrevendo-se como seres simbólicos. A relação com o espaço da dédicace promove os deslocamentos de sentido dos corpos ali envolvidos. Dessa forma, o corpo da persona do autor enquanto materialidade significa por meio do sujeito em uma posição-autor que assina a obra (um processo amparado pela materialidade daquele que recebe a obra assinada). Podemos dizer que sujeito e corpo só significam, no trabalho da linguagem, pela inscrição do sujeito em formações discursivas que corroboram as práticas autorais e autoriais, que as regulam e que as inscrevem no político, no histórico e no simbólico.

A problemática sobre a relação do nome verdadeiro com o pseudônimo, isso quer dizer, a função que esses nomes próprios exercem na sociedade, leva-nos a perguntar se é possível não estabelecer relação interdiscursiva entre sua dimensão ordinária e sua inevitável dimensão extraordinária (o nome de Autor). Enfim, vê-se que os nomes de Autor são nomes que transcendem seus portadores, seus sujeitos, e demandam refletirmos sobre a linguagem em seu funcionamento, na língua que os regula, que os constitui e os organiza também como discursividade.

\section{REFERÊNCIAS}

BAGNARIOL, P. Graffiti e quadrinhos na história da arte. In: BAGNARIOL, P. et al. Guia ilustrado de graffiti e quadrinhos. Belo Horizonte: Fapi, 2004, p. 5-74.

CISLARU, G. Le pseudonyme, nom ou discours ? D’Etienne Platon à Oxyhre. In: LECOLLE, M.; PAVEAU, M.-A.; REBOUL-TOURÉ, S. Les carnets du Cediscor: le nom propre en discours, n.11. Paris: PSN, 2009. p. 39-57. 
COSTA, L. P. A. Uma análise do discurso quadrinístico: práticas institucionais e interdiscurso. 2016. 223 f. Tese (Doutorado). Programa de Pós-Graduação em Estudos Linguísticos, Universidade Federal de Minas Gerais, Belo Horizonte, Minas Gerais, 2016.

COUTINHO, L. Cartunista Laerte diz que sempre teve vontade de se vestir de mulher. Entrevista concedida a Ivan Finotti. Folha de S. Paulo, 2010. Disponível em:

<http://www1.folha.uol.com.br/ilustrada/825136-cartunista-laerte-diz-que-sempre-teve-vontade-de-sevestir-de-mulher.shtml>. Acesso em: 7 maio 2016.

Crossdresser, travesti, trans: Laerte fala sobre sexualidade. Entrevista concedida a Bárbara

Therrie. Terra, 2015. Disponível em: <https://www.terra.com.br/vida-e-

estilo/mulher/comportamento/crossdresser-travesti-trans-laerte-fala-sobre-

sexualidade,c6d4497a0e2a8c81220e7b5168cb0bb15arfRCRD.html>. Acesso em: 28 maio 2017.

FOUCAULT, M. A arqueologia do saber. Trad. Luiz Felipe Baeta Neves. Rio de Janeiro: Forense Universitária, 2008.

O que é um autor?. In: FOUCAULT, M. Estética: literatura e pintura, música e cinema. Org. Manoel Barros da Motta. Trad. Inês Autran Dourado Barbosa. Rio de Janeiro: Forense Universitária, 2009, p. 264-298.

FRAENKEL, B. La signature: genèse d'un signe. Paris: Gallimard, 1992.

GREGOLIN, M. do R. V. Sentido, sujeito e memória: com o que sonha nossa vã autoria? In:

GREGOLIN, M. do R. V.; BARONAS, R. (Org.). Análise do discurso: as materialidades do sentido. São Carlos: ClaraLuz, 2003, p. 47-58.

Foucault e Pêcheux na análise do discurso: diálogos e duelos. São Carlos: ClaraLuz, 2004.

LECOLLE, M.; PAVEAU, M.-A.; REBOUL-TOURÉ, S. Les sens des noms propres en discours. In: LECOLLE, M.; PAVEAU, M.-A.; REBOUL-TOURÉ, S. Les carnets du Cediscor: le nom propre en discours, 11, 2009. Paris : PSN, 2009, p. 9-22.

MALDIDIER, D. A inquietação do discurso: (Re) ler Michel Pêcheux hoje. Trad. Eni P. Orlandi. São Paulo: Pontes, 2003.

ORLANDI, E. P. A linguagem e seu funcionamento: as formas do discurso. Campinas: Pontes, 1987. Discurso e leitura. São Paulo: Cortez/Unicamp, 1998.

2005. Interpretação: autoria, leitura e efeitos do trabalho simbólico. Rio de Janeiro, Petrópolis: Vozes,

PÊCHEUX, M. Semântica e discurso: uma crítica à afirmação do óbvio. Campinas: Editora da Unicamp, 2009.

PÊCHEUX, M.; FUCHS, C. A propósito da análise automática do discurso: atualização e perspectivas (1975). In: GADET, F.; HAK, T. (Org.). Por uma análise automática do discurso: uma introdução à obra de Michel Pêcheux. Trad. Bethania Mariani et al. 3. ed. São Paulo/Campinas: Editora da Unicamp, 1997.

STEFANELLI, M. Aux marges d'une ambiguïté médiaculturelle: quatre questions brûlantes pour une théorie culturelle de la bande dessinée. In: MAIGRET, É.; STEFANELLI, M. La bande dessinée: une médiaculture. Paris: Armand Colin, 2012. p. 253-266.

Recebido em: 31/05/17. Aprovado em: 25/02/18.

Title: Materialities of the authorship in the autograph session

Authors: Lucas Piter Alves-Costa; Marilda Aparecida Lachovski

Abstract: This paper aims to approximate the notions of author, authorship and enounced based, above all, on presuppositions from Foucault (2008, 2009) and COSTA (2016), in dialogue with Orlandi (1987, 1998, 2005), Gregolin (2003, 2004) and Pêcheux (2009), in order to problematize the double dimension of the author name, which are: the author seen as subject and as an enounced. Then, this work discusses some materialities of the author's name seen as an enounced. Thereunto, the discussion is based on the aspects of an autograph session of the Comics Discourse. The result of the reflections proposed reinforce the conceptualization of a complex enounced (COSTA, 2016) based on the function that the author's name plays in the discourses that are based on that name.

Keywords: Authorship. Complex enounced. Autograph session. Corporality. Signature. 
Título: Las materialidades de la autoría en la sesión de autógrafos

Autores: Lucas Piter Alves-Costa; Marilda Aparecida Lachovski

Resumen: Este artículo tiene por objetivo aproximar las nociones de autor, autoría y enunciación, desde sobretodo supuestos de Foucault (2008, 2009) y Costa (2016), en diálogo con Orlandi (1987, 1998, 2005), Gregolin (2003, 2004) y Pêcheux (2009), para entonces problematizar la doble dimensión del nombre de autor, es decir: el autor tomado como sujeto y como una enunciación. En seguida, este trabajo discute sobre algunas materialidades propias del nombre de autor mientras enunciación. Para ello, la discusión es guiada por aspectos de una sesión de autógrafos del discurso de historietas. Los resultados de las reflexiones aquí propuestas refuerzan la conceptuación de enunciación compleja (COSTA, 2016) desde la función que el nombre de autor desarrolla en los discursos que en él se fundan.

Palabras-clave: Autoría. Enunciación compleja. Sesión de autógrafos. Corporalidad. Firma.

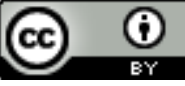

Este texto está licenciado com uma Licença Creative Commons Atribuição 4.0 Internacional. 